\title{
Thin Polyoxide on the Top of Poly-Si Gate to Suppress Boron Penetration for pMOS
}

\author{
Yung Hao Lin, Chung Len Lee, Senior Member, IEEE, Tan Fu Lei, and Tien Sheng Chao, Member, IEEE
}

\begin{abstract}
A method of using a thin oxide on the top of the poly-Si gate to getter fluorine for $\mathrm{BF}_{2}^{+}$in pMOS is proposed and demonstrated. Due to less amount of fluorine in the poly-Si as well as in the gate oxide, the boron penetration through the gate oxide is suppressed. The MOS capacitors fabricated by using this method show less shifts and distortion on $C-V$ curves and better electrical characteristics.
\end{abstract}

\section{INTRODUCTION}

$\mathbf{R}$ ECENTLY, the $\mathrm{p}^{+}$poly-Si gate has been widely used for submicrometer CMOS technology to avoid the shortchannel effects [1]. However, the boron used to dope this $\mathrm{p}^{+}$ poly-Si gate is easy to penetrate through the gate oxide into the underlying Si-substrate, especially for the $\mathrm{BF}_{2}^{+}$implanted poly-Si gate. This will cause the positive shift of the threshold voltage, increments of the gate oxide electron trapping rate, and the P-channel inverse subthreshold slope. Previously, we had proposed a stacked poly-Si gate structure with an ultra-thin oxide inserted in-between to suppress the boron penetration [2], [3]. It had also been found that the inclusion of a $\mathrm{TiSi}_{2}$ salicide prior to the gate implantation can eliminate the fluorine-related $V_{\mathrm{fb}}$ shifts [4] and fluorine is primarily to segregate at the oxide and the defect region after the postimplant annealing process [5]. In this work, a thin polyoxide is to replace the $\mathrm{TiSi}_{2}$ salicide on the top of the poly-Si gate. In the post-implant annealing process, this thin oxide will getter fluorine out of the poly-Si gate, hence reduce the amount of fluorine in the poly-Si as well as in the gate oxide [3]. Thus, the enhancement on the boron penetration by fluorine is reduced [6]. Hence, the gate oxide prepared by this process has better electrical characteristics.

\section{EXPERIMENTALS}

The $\mathrm{p}^{+}$poly-Si gate MOS capacitors were fabricated on (100), $5 \sim 10 \Omega$-cm, n-type $S i$ wafers with a $88 \AA$ gate oxide. The gate oxide was grown in diluted dry $\mathrm{O}_{2}\left(\mathrm{O}_{2} / \mathrm{N}_{2}=1 / 6\right)$ at $900^{\circ} \mathrm{C}$ and annealed in $\mathrm{N}_{2}$ at the same temperature for $15 \mathrm{~min}$. After that, $3000 \AA$ of undoped polysilicon was deposited and a thin polyoxide $(\sim 100 \AA)$ was grown on the top of the deposited polysilicon layer (OTP) in $\mathrm{O}_{2}$ at $900^{\circ} \mathrm{C}$ for $10 \mathrm{~min}$. For

Manuscript received August 18, 1994; revised February 2, 1995. This work was supported by the National Science Council of ROC under Contract NSC84-2215-E009-003.

Y. H. Lin, C. L. Lee, and T. F. Lei are with the Department of Electronics Engineering and Institute of Electronics, National Chiao Tung University, Hsinchu 30050, Taiwan, ROC.

T. S. Chao is with National Nano Device Laboratory, Hsinchu, Taiwan, ROC

IEEE Log Number 9410651. comparison, control samples without the polyoxide were also fabricated. Then, all the samples were implanted with $\mathrm{BF}_{2}^{+}$of a dose $5 \times 10^{15} \mathrm{~cm}^{-2}$ at $50 \mathrm{KeV}$, and annealed at $800^{\circ} \mathrm{C}$ in $\mathrm{O}_{2}$ for $30 \mathrm{~min}$ first and then at $900^{\circ} \mathrm{C}$ in $\mathrm{N}_{2}$ for $10,20,30$, and 40 min respectively, to activate the implanted dose. The oxidizing anneal at $800^{\circ} \mathrm{C}$ was intended to grow a thin polyoxide on the poly-Si gate to prevent the boron out-diffusion during the latter inert annealing at $900^{\circ} \mathrm{C}$. After the polyoxide was removed, $\mathrm{Al}$ was deposited and annealed at $400^{\circ} \mathrm{C}$ in $\mathrm{N}_{2}$ for $30 \mathrm{~min}$ to make capacitors. The area of capacitors was $4.324 \times 10^{-3} \mathrm{~cm}^{2}$. The boron and fluorine profiles of the samples were analyzed with SIMS and a Keithley C-V analyzer was used to measure the high frequency $(100 \mathrm{KHz})$ and quasi-static capacitances of the capacitors.

\section{RESULTS AND DisCUSSIONS}

Fig. 1 shows the fluorine and boron profiles of the OTP and control samples after annealing, respectively. The control sample had two fluorine peaks, one at the location of the gate oxide, and the other at the $\mathrm{BF}_{2}^{+}$implant region. For the OTP sample, the fluorine peak at the implant region disappeared and the fluorine which segregated at the gate oxide had a lower peak, about 0.7 of that of the control sample. The polyoxide on the top of the poly-Si-had acted as a sink for fluorine, thus reduced the fluorine in the poly-Si gate and the gate oxide. Since fluorine enhances the boron diffusion in oxide [6], this less fluorine in the OTP gate had a less boron penetration [3]. This is seen that the OTP sample had the boron peak at the gate oxide about 0.65 of that of the control sample and a shallower profile in the $\mathrm{Si}$ substrate.

Fig. 2(a) and (b) show the normalized high frequency (100 $\mathrm{KHz}$ ) and quasi-static C-V curves for the OTP and control samples annealed for different times, respectively. It is seen that the shifts of the $C-V$ curves, which were due to the negative fixed charge generated by F-B complexes and a very shallow P-type layer in the silicon substrate as a result of the boron penetration [4], of the OTP samples were much less than those of control samples. For the control sample of 40 min annealing, the high frequency $\mathrm{C}-\mathrm{V}$ curve had distorted so much that a shallow P-type layer had formed, due to the boron penetration, underlying the gate oxide and the sample acted like an nMOS capacitor. However, for the OTP sample of the same annealing, the shape of the high frequency $\mathrm{C}-\mathrm{V}$ curve stayed still the same except that it shifted to the right a little.

It is noted that although the polyoxide on the poly-Si gate gettered boron thus reduced the amount of boron in the poly- $\mathrm{Si}$ 


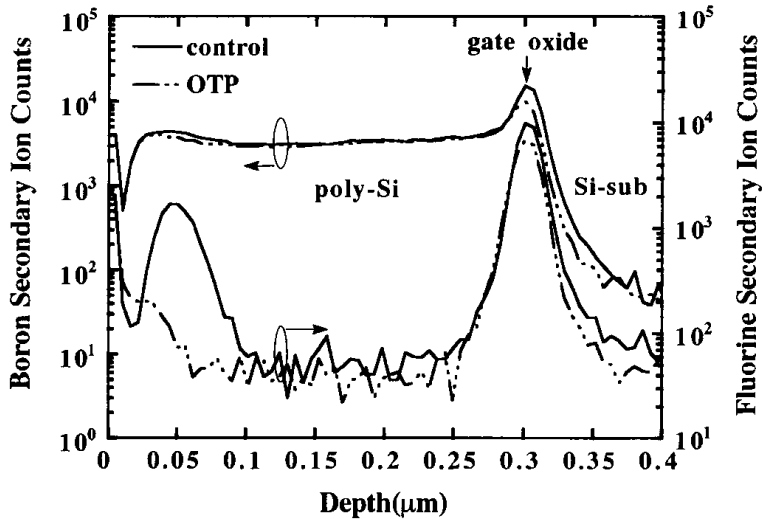

Fig. 1. The SIMS depth profiles of fluorine and boron for the OTP and control samples annealed in $\mathrm{O}_{2}$ at $800^{\circ} \mathrm{C}$ for $30 \mathrm{~min}$ then in $N_{2}$ at $900^{\circ} \mathrm{C}$ for $40 \mathrm{~min}$ after the $\mathrm{BF}_{2}^{+}$implantation.

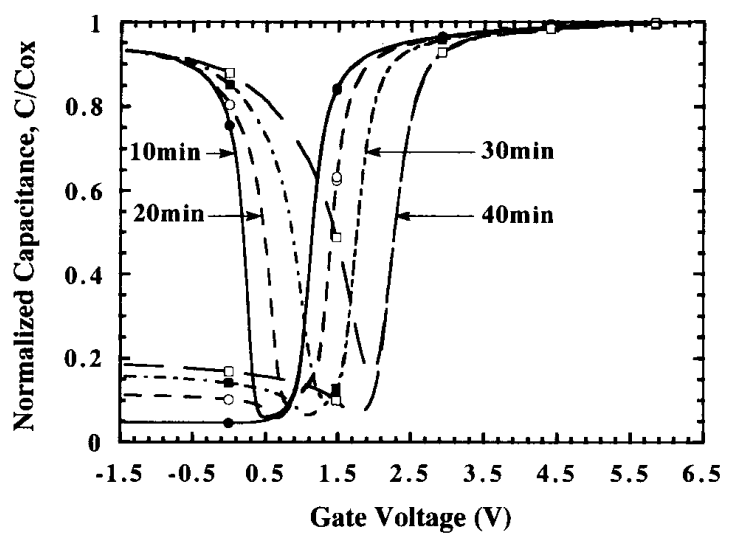

(a)

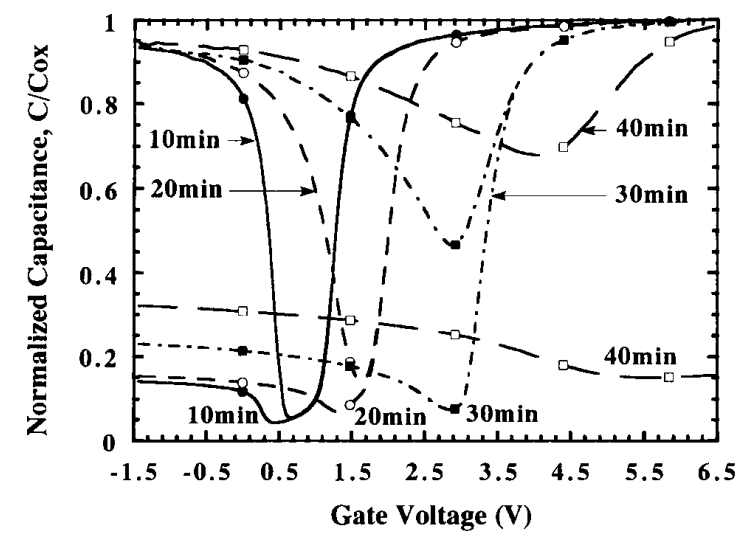

(b)

Fig. 2. The normalized high frequency $(100 \mathrm{KHz})$ and quasi-static $\mathrm{C}-\mathrm{V}$ curves of the (a) OTP samples, and (b) control samples annealed at $900^{\circ} \mathrm{C}$ for different times.

gate, the poly-Si depletion effect did not occur, which is seen from the $\mathrm{C}-\mathrm{V}$ curves for the OTP samples. The $C_{\mathrm{qs}, \text { inv }} / C_{\mathrm{ox}}$

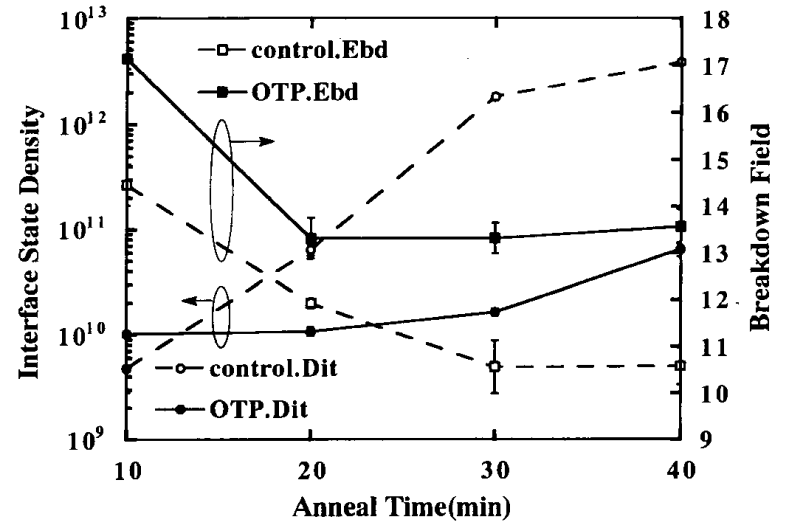

Fig. 3. The mid-gap interface state densities (state $/ \mathrm{cm}^{2} / \mathrm{eV}$ ) and breakdown fields $(\mathrm{MV} / \mathrm{cm})$ for the OTP and control samples, annealed at $900^{\circ} \mathrm{C}$ for different times.

values were all between 0.95 and 0.935 , and were nearly the same for both the OTP and the control samples.

Fig. 3 lists the mid-gap interface state densities $\left(D_{\mathrm{it}}\right)$ and the breakdown fields $\left(E_{\mathrm{bd}}\right)$ for the OTP and control samples annealed for different times. For both $D_{\text {it }}$ and $E_{\text {bd }}$, the OTP samples had much better results than that of control samples. This was due to the less fluorine, consequently, less boron at the gate oxide [6], which kept a better integrity of the oxide, for the OTP samples.

\section{CONCLUSION}

In conclusion, by growing a thin polyoxide on the top of the poly-Si gate, as the experimental results show, can getter fluorine out of the poly-Si gate during the post-implant annealing process. As a result, less fluorine segregate at gate oxide, and thus the boron penetration is suppressed. This improves the characteristics and also the reliability of pMOSFET.

\section{REFERENCES}

[1] H. H. Tseng, P. J. Tobin, F. K. Baker, J. R. Pfiester, K. Evans, and P. L. Fejes, "The effect of silicon gate microstructure and gate oxide process on threshold voltage instabilities in $\mathrm{p}^{+}$-gate $\mathrm{p}$-channel MOSFET's with fluorine incorporation, IEEE Trans. Electron Devices, vol. 39, p. 1687, 1992.

[2] S. L. Wu, C. L. Lee, and T. F. Lei, "Suppression of the boron penetration induced $\mathrm{Si} / \mathrm{SiO}_{2}$ interface degradation by using a stacked-amorphoussilicon film as the gate structure for pMOSFET," IEEE Electron Device Lett., vol. 5 , p. 160,1994

[3] Y. H. Lin, C. L. Lee, T. F. Lei, and T. S. Chao, "Suppression of boron penetration in pMOS by using oxide gettering effect in poly-si gate," Extended Abstracts Conf. SSDM, Japan, p. 685, 1994, and Jpn. J. Appl. Phys., vol. 34, part 1, no. 2B, p. 142, 1995

[4] F. K. Baker, J. R. Pfiester, T. C. Mele, H.-H. Tseng, P. J. Tobin, J. D. Hayden, C. D. Gunderson, and L. C. Parrillo, "The influence of fluorine on threshold voltage instabilities in $\mathrm{P}^{+}$polysilicon gate $\mathrm{P}$-Channel MOSFETs," IEDM, p. 443, 1989.

[5] T. Kinoshita, M. Takakura, S. Miryazaki, S. Yokoyama, M. Koyanagi, and $M$. Hirose, "Chemical bonding features of fluorine and boron in BF2+-ion-implanted Si," Jpn. J. Appl. Phys., vol. 29, p. L2349, 1990.

[6] J. J. Sung and C. Y. Lu, "A comprehensive study on $\mathrm{p}^{+}$polysilicongate MOSFET's instability with fluorine incorporation," IEEE Trans. Electron Devices, vol. 37, p. 2312, 1990. 